\title{
Bacterial cellulose as a source for activated nano-sized carbon for electric double layer capacitors
}

Koon-Yang Lee ${ }^{1}$, Hui Qian ${ }^{1}$, Feng H. Tay ${ }^{2}$, Jonny J. Blaker ${ }^{1}$, Sergei G. Kazarian ${ }^{2}$ and Alexander Bismarck $^{1 *}$

${ }^{1}$ Polymer and Composite Engineering (PaCE) Group

${ }^{2}$ Vibrational Spectroscopy and Chemical Imaging Group

Department of Chemical Engineering, Imperial College London, South Kensington Campus, SW7 2AZ, UK

\begin{abstract}
A nano-sized carbonaceous material was derived from bacterial cellulose (BC). $\mathrm{BC}$, which is produced by bacteria as nano-sized material, possesses high degree of crystallinity of $90 \%$, was pyrolysed at $950^{\circ} \mathrm{C}$ and physically activated with $\mathrm{CO}_{2}$ to produce a nano-sized activated carbon material. The pyrolysis of $\mathrm{BC}$ yielded a carbonaceous material (carbon yield of between $2 \%$ and $20 \%$ ), with a relatively low D- to G-band ratio (between 2.2 and 2.8), indicating that the carbonaceous material possesses a graphitic structure. Two different $\mathrm{BC}$ materials were pyrolysed; a loose fibrous (freeze-dried) and dense paper form. It was observed that a carbon nanofibre-like material was produced by the pyrolysis of the loose fibrous form of $\mathrm{BC}$. The electric double layer (EDL) capacitance and the area-normalised specific capacitance in $\mathrm{K}_{2} \mathrm{SO}_{4}$ solution were as high as $42 \mathrm{~F} \mathrm{~g}^{-1}$ and $1617 \mathrm{~F} \mathrm{~cm}^{-2}$, respectively. The EDL capacitance was also compared to commercially available activated carbon (YP-50F).
\end{abstract}

Keywords: Bacterial cellulose, carbonization, electric double layer capacitor, nanocellulose, activation

* Corresponding author. Tel: $+44(0) 207594$ 5578, Fax: $+44 \quad(0) 207594$ 5638. Email address: a.bismarck@imperial.ac.uk (A. Bismarck) 


\section{Introduction}

Energy storage devices can be categorised into three categories; fuel cells, batteries and capacitors. Conventional batteries have high energy density but low power density [1]. This implies that batteries are able to store sufficient energy for commercial use but deliver low power. On the other hand, conventional capacitors possess high power density and hence, capacitors are able to deliver high power [2] yet store little energy. It is highly desirable to manufacture energy storage devices that combine both high energy and power densities such that they can store sufficient energy and are able to deliver high power. Therefore, numerous research efforts have been directed into the development of high power batteries [3,4] and supercapacitors [5-7,2,8]. Supercapacitors or electric double layer capacitors (EDLC) utilise the electrochemical double layer formed between a solid surface and an electrolyte solution to store energy [5]. ELDC have numerous advantages over conventional batteries and capacitors, such as a longer cycle life [7], higher energy densities [8] and rapid energy charge-discharge cycles [9].

Metal oxides [10,11] and polymers [12,13] have been considered as active electrode materials for EDLC. However, activated carbons remain the most frequently used electrode material for EDLC. Activated carbons are usually derived from coal, wood, coconut shells and fruit stones [14]. These carbons are low cost, have high surface areas $\left(\sim 2500 \mathrm{~m}^{2} \mathrm{~g}^{-1}\right)$, are widely available and have an established electrode production technology [9]. Carbon nanotubes (CNT) are also a potential candidate as the active electrode for EDLC due to their high specific surface area and good conductivity [15-18]. More recently, the utilisation of lignocellulosic fibres as a carbon source for EDLC has been studied extensively [19-21]. Lignocellulosic fibres have attracted much attention due to their wide availability, low cost and porous nature, which usually results in high surface area of the carbon produced after pyrolysis and physical activation. Various types of lignocellulosic fibres have been studied as potential activated carbon source; 
wood [22], wheat straw [20], cotton stalk [23-25], jute [26], oil palm [27], coconut husk [28] and sea grass [29] fibres.

Studies have also been conducted on the carbonisation of nano-sized cellulose, namely bacterial cellulose (BC) and tunicate derived cellulose whiskers [30-32]. The syntheses of mesoporous carbon and carbon nano-needles from cellulose nanowhiskers have also been reported recently in literature $[33,34]$. The study on the carbonisation of bacterial cellulose however, focused on the effects of drying the cellulose from different solvents on the surface area of the carbonised cellulose. To the best of our knowledge, no studies have been performed to evaluate the physical activation of pyrolysed nano-sized $\mathrm{BC}$ and its application for EDLC. Here we provide a comprehensive investigation into the physical properties of physically activated carbonaceous nanomaterials derived from $\mathrm{BC}$ and its potential application as an active electrode material for EDLC. The capacitance of the carbon produced by the pyrolysis of BC was compared with the capacitance of commercially available activated carbon for supercapacitors (YP-50F).

\section{Experimental}

\subsection{Materials}

Potassium sulphate $\left(\mathrm{K}_{2} \mathrm{SO}_{4}\right)$ solution (Fluka, $0.5 \mathrm{M}$ in water) was purchased from Sigma-Aldrich. Hydrochloric acid (Alfa Aesar, 0.1 N), potassium hydroxide (Alfa Aesar, 0.1 N) and acetylene black (50\% compressed, purity $>99.9 \%$, Alfa Aesar) were purchased from VWR. Sodium hydroxide (purum grade, pellets) was purchased from Acros Organics. Polytetrafluoroethylene (Fluon $\left.{ }^{\circledR}\right)$ was purchased from AGC Chemicals. Carbon nanofibres (CNF) and a high surface area activated carbon (YP-50F) were used as benchmark for comparison and were kindly supplied by Pyrograf Products Inc (PR-19 PS, Cerdaville, Ohio, USA) and Kuraray Chemicals (Canoga Park, 
CA, USA), respectively. Nitrogen (purity $\geq 99.998 \%$ ) and carbon dioxide (purity $\geq 99.8 \%$ ) were purchased from BOC (Morden, UK). All the materials were used as received without further purification. Bacterial cellulose was extracted from commercially available Nata-de-Coco (CHAOKOH coconut gel in syrup, Ampol Food Processing Ltd, Nakorn Pathom, Thailand).

\subsection{Extraction and purification of bacterial cellulose}

The extraction and purification of BC from Nata-de-Coco was reported elsewhere [35]. Briefly, the Nata-de-Coco gels from 5 jars of Nata-de-Coco were rinsed 3 times with $5 \mathrm{~L}$ of de-ionised water to remove the majority of the sugar syrup. After this washing step, the gels were blended for $1 \mathrm{~min}$ in $5 \mathrm{~L}$ of de-ionised water using a laboratory blender (Waring Blender LB20EG, Christison Particle Technology, Gateshead, UK) and homogenised for 2 min (Polytron PT 10-35 GT, Kinematica, Lucerne, Switzerland). The homogenised gel was centrifuged at $14,000 \mathrm{~g}$ to remove the excess water. In order to obtain pure $\mathrm{BC}$, the centrifuged $\mathrm{BC}$ gel was purified by redispersing it in $5 \mathrm{~L}$ of $0.1 \mathrm{M} \mathrm{NaOH}$ solution, heated to $80^{\circ} \mathrm{C}$ for $20 \mathrm{~min}$ to remove any soluble polysaccharides and microorganisms [36]. This purified BC was then successively centrifuged and homogenised using de-ionised water to neutral $\mathrm{pH}$.

\subsection{Preparation of freeze-dried $\mathrm{BC}$ and dense $\mathrm{BC}$ paper}

$\mathrm{BC}$ was prepared in two different forms prior to pyrolysis; as loose nanofibrils (freeze-dried) and in dense paper form. Freeze dried BC was prepared by dispersing the previously extracted and purified $\mathrm{BC}$ in water at a concentration of $0.4\left(\mathrm{~g} \mathrm{~mL}^{-1}\right) \%$ using a homogeniser. The dispersion was poured into a Petri dish, flash frozen in liquid nitrogen and freeze-dried (Heto PowerDry LL1500 Freeze Dryer, Thermo Scientific, UK).

Dense BC paper was manufactured following BS EN ISO 5269:2005. The previously extracted and purified $\mathrm{BC}$ was dispersed in water at a concentration of $0.1\left(\mathrm{~g} \mathrm{~mL}^{-1}\right) \%$ using a 
homogeniser. This dispersion was filtered under vacuum using a filter paper (diameter: $125 \mathrm{~mm}$, particle retention: $5-13 \mu \mathrm{m}, \mathrm{VWR}$, Lutterworth, UK). The filter cake was wet pressed 3 times at a force of $410 \mathrm{kN}$. The wet pressed filter cake was then dried at room temperature at $50 \% \mathrm{RH}$ to produce a dense BC paper. The loose fibrous (freeze-dried) BC and dense (paper) BC are referred to as FDBC and BCP, respectively, hereafter.

\subsection{Pyrolysis and physical activation of $\mathrm{BC}$}

$\mathrm{BC}$ was pyrolysed and physically activated in a chamber furnace (ECF 12/30, 28 L chamber capacity, Lenton, Hope Valley, UK). Prior to the pyrolysis of $\mathrm{BC}$, the furnace was purged with $\mathrm{N}_{2}$ at $2 \mathrm{~L} \mathrm{~min}^{-1}$ for $15 \mathrm{~min}$. BC was pyrolysed at $950^{\circ} \mathrm{C}$ for $30 \mathrm{~min}$ under continuous $\mathrm{N}_{2}$ flow $(2 \mathrm{~L}$ $\min ^{-1}$ ) at a heating rate of $5^{\circ} \mathrm{C} \min ^{-1}$. Physical activation of $\mathrm{BC}$ consisted of a pyrolysis step at $950^{\circ} \mathrm{C}$ for $30 \mathrm{~min}\left(2 \mathrm{~L} \mathrm{~min}^{-1}\right.$ of $\mathrm{N}_{2}$ flow), directly followed by an activation step in $\mathrm{CO}_{2}(0.5 \mathrm{~L}$ $\min ^{-1}$ ) for $10 \mathrm{~min}$. The pyrolysed FDBC and BCP were termed carbonised FDBC and carbonised $\mathrm{BCP}$, respectively, whereas the physically activated pyrolysed FDBC and BCP were termed activated FDBC and activated BCP, respectively. The carbon yield or burn-off was calculated using the equations below:

$$
\begin{aligned}
& \Delta Y=\left(1-\frac{w_{i}-w_{f}}{w_{i}}\right) \times 100 \% \\
& \Delta m=\frac{w_{i}-w_{f}}{w_{i}} \times 100 \%
\end{aligned}
$$

where $\Delta Y$ is the carbon yield and $\Delta m$ is the burn-off, $w_{i}$ is the initial mass before pyrolysis/physical activation and $w_{f}$ is the mass after pyrolysis/physical activation, respectively.

\subsection{Characterisation of $\mathrm{BC}$, carbonised $\mathrm{BC}$ and $\mathrm{CNF}$}

\subsubsection{Scanning electron microscopy (SEM)}


SEM was performed using a high-resolution field emission gun scanning electron microscope (LEO Gemini 1525 FEG-SEM, Oberkochen, Germany). It was used to characterise the morphology of $\mathrm{BC}$ before and after pyrolysis and physical activation. The accelerating voltage used during SEM was $5 \mathrm{kV}$. Prior to SEM, all the samples were fixed onto SEM stubs using carbon tabs and Cr coated with a sputter coater (K550 sputter coater, Emitech Ltd, Ashford, Kent, UK) for $1 \mathrm{~min}$ at $75 \mathrm{~mA}$.

\subsection{2 $\zeta$-potential measurements}

The $\zeta$-potentials of neat, pyrolysed, activated pyrolysed $\mathrm{BC}$ and $\mathrm{CNF}$ were measured using the electrokinetic analyser (EKA, Anton Paar, Graz, Austria) based on the streaming potential method in a powder cell. In order to exclude any overlaying effects due to swelling (for BC) or extraction of water-soluble components from the samples, the $\mathrm{pH}$ dependency of $\zeta$-potential was measured only after a time dependent $\zeta$-potential measurement was completed. During the $\zeta=$ $\mathrm{f}(t)$ measurement, a sample mass of approximately $50 \mathrm{mg}$ was equilibrated in $1 \mathrm{mM} \mathrm{KCl}$ electrolyte solution by means of a single long time streaming $\zeta$-potential measurement at $20^{\circ} \mathrm{C}$. The $\mathrm{pH}$ dependency of the $\zeta$-potential was then measured by changing the $\mathrm{pH}$ of the electrolyte solution through the titration of $0.1 \mathrm{~N} \mathrm{HCl}$ or $\mathrm{KOH}$ into $\mathrm{KCl}$ solution, using a titration unit (RTU, Anton Paar, Graz, Austria).

\subsubsection{Specific surface area (BET) measurements}

Nitrogen adsorption/desorption isotherms were performed to determine the specific surface area of neat, pyrolysed, activated pyrolysed $\mathrm{BC}$ and CNFs using a surface area and porosity analyser (TriStar 3000, Micrometrics Ltd, Dunstable, UK). The specific surface area was calculated using the Brunauer-Emmett-Teller (BET) equation. Prior to the measurement, the samples were degassed at $80^{\circ} \mathrm{C}$ overnight to remove adsorbed water molecules. 


\subsubsection{Density measurements}

The densities of neat, pyrolysed, activated pyrolysed BC and CNFs were measured using He pycnometry (Accupyc 1330, Micrometrics Ltd, Dunstable, UK). The samples were weighed $($ A\&D GH-252, resolution $=0.01 \mathrm{mg}$, Milton Keynes, UK) prior to placing them into the measuring chamber of the pycnometer. As the pressure of He rises above atmospheric value, it was expanded through a valve and this expanded volume was measured. Due to the expansion of He, the pressure inside the chamber will decrease to a constant value. By assuming that He obeys the ideal gas law, the density of the sample was then calculated using the equation:

$$
\rho=\frac{m}{V_{c}-\frac{V_{E}}{\frac{P_{1}}{P_{2}}-1}}
$$

where $m$ is the sample mass, $V_{c}$ the chamber volume, $V_{E}$ the expanded helium volume, $P_{1}$ and $P_{2}$ are the chamber's elevated pressure and constant pressure, respectively.

\subsubsection{Thermal gravimetric analysis (TGA)}

The thermal degradation behaviour of neat, pyrolysed, activated pyrolysed BC and CNFs was characterised using TGA (TGA Q500, TA Instruments, UK). Samples of $5 \mathrm{mg}$ were heated from $20^{\circ} \mathrm{C}$ to $700^{\circ} \mathrm{C}$ in air at a heating rate and air flowrate of $10^{\circ} \mathrm{C} \mathrm{min}{ }^{-1}$ and $60 \mathrm{~mL} \mathrm{~min}^{-1}$, respectively.

\subsubsection{Raman spectroscopy}

Raman spectroscopy was performed using a dispersive Renishaw 1000 confocal microscope (Reinshaw Plc, Hillesley, Wotton-under-Edge, UK). An argon ion laser $(\lambda=514.5 \mathrm{~nm})$, which has a maximum output power of $20 \mathrm{~mW}$ and a spot size of $1 \mu \mathrm{m}$, was used for this characterisation. The laser was focussed onto the sample using a $50 \times$ objective at ambient condition and the spectra were measured with a collection time of $60 \mathrm{~s}$ and 10 co-additions at 
$10 \%$ of the laser power from $2000 \mathrm{~cm}^{-1}$ to $1000 \mathrm{~cm}^{-1}$. Each sample was characterised at three randomly selected locations. The Raman spectra were peak fitted using a mixed GaussianLorentzian (G/L ratio of 30:70) curve in order to extract the structural parameter. D- to G-band ratio $\left(\mathrm{I}_{\mathrm{D}} / \mathrm{I}_{\mathrm{G}}\right)$ was calculated by taking the integrated area under the fitted curves corresponding to

the D-band $\left(1350 \mathrm{~cm}^{-1}\right)$ and G-band $\left(1590 \mathrm{~cm}^{-1}\right)$, respectively. The in-plane graphitic crystallite size [37] $L_{a}$ was calculated from the D- to G-band intensity ratio using equation 3 . This equation is valid for a Raman laser with $(\lambda=514.5 \mathrm{~nm})[38]$.

$$
L_{a}[n m]=4.4 \times\left(\frac{I_{D}}{I_{G}}\right)^{-1}
$$

\subsubsection{Determination of the electric double layer capacitance}

Cyclic voltammetry $(\mathrm{CV})$ was performed to characterise the double layer capacitance of the produced carbonaceous materials. It was conducted using an electrochemical measurement system (Solartron 1287, Solartron Analytical, Farnborough, UK) with a three-electrode cell. Pt wire and $\mathrm{Ag} / \mathrm{AgCl}$ electrodes were used as the counter and reference electrodes, respectively. In order to fabricate the working electrode, the samples were dispersed along with acetylene black and polytetrafluoroethylene (PTFE) at a ratio of $87 \mathrm{wt} \%: 10 \mathrm{wt} \%: 3 \mathrm{wt} \%$ in ethanol using an ultrasonic bath. The slurry was then applied onto two flat nickel foams (RCM-4573, RECEMAT International $\mathrm{BV}$ ). The foams coated with the carbon material were dried at $40^{\circ} \mathrm{C}$ overnight to remove any residual ethanol, then sandwiched and compressed under a weight of $250 \mathrm{~kg}$ for 5 min. Acetylene black was used to reduce the Ohmic resistivity of the active electrode material [39] and PTFE as binder. It has been shown that acetylene black does not affect the capacitance of the active electrode material [40]. The double layer capacitance was measured in a $0.5 \mathrm{M}$ $\mathrm{K}_{2} \mathrm{SO}_{4}$ electrolyte solution. CV profiles were obtained between $-0.2 \mathrm{~V}$ and $0.2 \mathrm{~V}$ at various scan rates $\left(1 \mathrm{mV} \mathrm{s}^{-1}, 5 \mathrm{mV} \mathrm{s}^{-1}, 10 \mathrm{mV} \mathrm{s}^{-1}\right.$ and $\left.20 \mathrm{mV} \mathrm{s}^{-1}\right)$. The capacitance was calculated using: 
$C=\frac{I_{a}-I_{c}}{2 \times m \times \frac{d E}{d t}}$

where $C, I_{a}, I_{c}, m$ and $\frac{d E}{d t}$ are the specific double layer capacitance, the current corresponds to the anodic and cathodic part of the CV curves, mass of the active samples and the scan rates, respectively.

\section{Results and discussion}

\subsection{BET surface area of neat $\mathrm{BC}$ and $\mathrm{BC}$ derived carbon}

The properties of both BC starting materials, i.e. dense paper and loose freeze-dried (see Fig 1), and the carbon samples produced from $\mathrm{BC}$ are given in Table 1. It should be noted that the table does not contain the properties of carbonised and activated freeze-dried bacterial cellulose (FDBC). This is a direct result of low carbon yield $(\sim 2.3 \%)$ and large surface area $\left(\sim 166 \mathrm{~m}^{2} \mathrm{~g}^{-1}\right)$ of carbonised FDBC. The physical activation of the carbon using $\mathrm{CO}_{2}$ involves the burning off of carbonaceous material to produce pores, with $\mathrm{CO}$ as a by-product [14]. As a result of the high burn-off after pyrolysis, the physical activation process will remove any residual material left over after the pyrolysis of FDBC. It is, however, possible to physically activate carbonised bacterial cellulose paper (BCP) as it had a higher carbon yield and smaller exposed surface area (see Table 1). It can also be seen from Table 1 that the carbon yield of BCP is substantially higher than that of FDBC, which might be a direct result of the exposed surface area.

The total surface area of the samples (carbonised FDBC, carbonised BCP and activated pyrolysed BCP) increased when it was pyrolysed/carbonised and physically activated (see Table 1). The BET surface area of our carbon materials is in agreement with the surface area of activated carbon produced by pyrolysis and activation of lignin and lignocellulosic material (sea 
grass), respectively [29]. The pyrolysis and activation process increased the pore area more significantly compared to the external surface area for all carbon samples (Table 1). The diffusion of $\mathrm{CO}_{2}$ into the sample removes amorphous carbon and created a porous structure within the sample through the formation of $\mathrm{CO}$ [14]. It is well known that the pyrolysis process will result in micropore and mesopore formation [26], whereas the activation process will widen existing pores [41].

\subsection{Morphology of carbonised BC}

The SEM images of the samples produced from BC are shown in Fig 1. FDBC possesses a fibrous structure, with a diameter of approximately $50 \mathrm{~nm}$ and several micrometres in length (Fig 1a). When FDBC is pyrolysed, the carbon retains the fibrous structure of the BC precursor (Fig 1b). The pyrolysis of FDBC produced a carbon nanofibre-like material. Fig 1(c) and Fig 1(d) show the morphology of pyrolysed $\mathrm{BCP}$ and activated pyrolysed $\mathrm{BCP}$, respectively. There is no observable porosity in the pyrolysed $\mathrm{BCP}$. The physical activation of carbonised $\mathrm{BC}$ paper, on the other hand, produced a porous structure within the sample.

\section{$3.3 \mathrm{pH}$ dependent streaming $\zeta$-potential behaviour of $\mathrm{BC}$ and $\mathrm{BC}$ derived carbon}

$\zeta$-potential provides information regarding the surface chemistry of a material and the formation and composition of the double layer when this material is in contact with an electrolyte solution. The $\zeta$-potential is generally assumed to approximate the electrochemical potential at the boundary between the immobile (Stern) layer and the diffusive (Gouy) part of the double layer [42]. Fig 2 shows the streaming $\zeta$-potential of $\mathrm{BC}$ and carbonised $\mathrm{BC}$ samples in a $\mathrm{KCl}$ electrolyte as a function of $\mathrm{pH}$. The formation of electrochemical double layer is predominantly due to the adsorption of electrolyte ions onto the surface and the dissociation of Brønstedt acid/base groups. Generally, $\zeta$-potential shows a plateau at high $\mathrm{pH}$ for acidic surfaces or a 
plateau at low $\mathrm{pH}$ for basic surfaces as all dissociable functional groups are either fully deprotonated for the case of acidic surfaces $\left(\mathrm{COO}^{-}\right)$or fully protonated for the case of basic surfaces and basic oxides. In this study, a negative $\zeta_{\text {plateau }}$ can be seen for BC and cellulose derived carbonaceous material (with the exception of $\mathrm{CNF}$ ). This is an indication that the surface of the substrate has an acidic surface character due to the deprotonation of functional groups occurring at high $\mathrm{pH}$. As the $\mathrm{pH}$ decreased, the $\zeta$-potential becomes more positive due to (i) protonation of functional groups and (ii) adsorption of protons $\left(\mathrm{H}_{3} \mathrm{O}^{+}\right)$. CNFs on the other hand, possess a basic surface (Fig 2), as indicated by a positive $\xi_{\text {plateau. }}$ This is consistent with the $\xi$ potentials measured for oxidised carbon fibres [43]. At $\mathrm{pH}$ of between 5 and 9 , the surface is positively charged (positive $\zeta$-potential value). This is indicative that the surface contains functional groups, such as basic oxides [44]. The $\zeta$-potential increased drastically as $\mathrm{pH}$ decreased from 5.5 to 3 due to the adsorption of protons.

Table 2 tabulates the isoelectric points iep, the point at which no net charge is present on the surface $(\zeta=0)$, and the $\zeta$-potential plateau values. The iep of BCP is higher than that of FDBC due to the fact that more hydroxyl groups are involved in the hydrogen bonding of the cellulose to form a dense paper. This resulted in a reduced amount of exposed hydroxyl groups and therefore a higher iep compared to FDBC. It also can be seen that the iep of BC (FDBC and $\mathrm{BCP}$ ) shifted to higher $\mathrm{pH}$ upon carbonisation and physical activation. The shift of the iep to higher $\mathrm{pH}$ is a result of the decomposition of dissociable functional groups due to the pyrolysis of BC. Ishimaru et al. [45] have studied the carbonisation behaviour of cotton cellulose. It was found that dehydration, decarbonylation and decarboxylation on cellulose are the major reactions that occur between $800^{\circ} \mathrm{C}$ and $1000^{\circ} \mathrm{C}$. The hydroxyl groups on $\mathrm{BC}$ are decomposed during pyrolysis, leading to an increase in the iep towards higher $\mathrm{pH}$. In addition to this, the high oxygen 
to carbon ratio of $\mathrm{BC}$ will lead to the development of oxygen-containing functional groups and crosslinking of polyaromatic stacks after pyrolysis [45-47]. The crosslinking of the polyaromatic stacks led to a more hydrophobic surface. Both of these factors led to the observed decrease of $\zeta_{\text {plateau }}$ after pyrolysis. This is because water molecules do not like to adsorb on the hydrophobic carbon surface, on which now more electrolyte ions adsorb.

It can also be seen that the magnitude of the $\zeta_{\text {plateau }}$ increased from $-12.5 \mathrm{mV}$ to $-5 \mathrm{mV}$. The physical activation increased the hydrophilic character of activated carbon, as indicated by

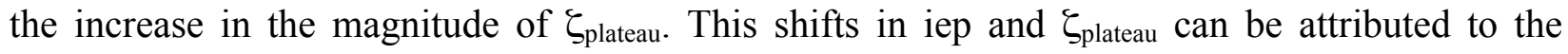
changes in chemical structure of the surface and the decrease in acidic functional groups as a result of physical activation. This result is consistent with the findings obtained by Julien et al. [48], who found that the magnitude of $\zeta_{\text {plateau }}$ increased with increasing activation temperature due to the burn off of functional groups from activated carbon.

\subsection{Thermal behaviour of $\mathrm{BC}$ and carbon samples derived from $\mathrm{BC}$}

Fig 3 shows the thermal degradation behaviour of neat BC and carbon samples produced from $\mathrm{BC}$ in air. Their onset thermal degradation temperatures are tabulated in Table 2. Two distinct weight loss steps for both $\mathrm{BC}$ forms; FDBC and $\mathrm{BCP}$, can be observed, indicating two different types of thermal decompositions. The initial weight loss between $300^{\circ} \mathrm{C}$ and $350^{\circ} \mathrm{C}$ can be attributed to the decomposition of smaller molecular fragments on $\mathrm{BC}$ and the second decomposition $\left(350^{\circ} \mathrm{C}-500^{\circ} \mathrm{C}\right)$ is attributed to the degradation of the six-member cyclic structure of cellulose (pyran) [49,50]. Different thermal degradation behaviour can be seen between FDBC and BCP. Um et al. [51] studied the degradation behaviour of silk fibres and found that the thermal degradation behaviour of the material depends on its crystallinity, molecular weight and molecular orientation of the cellulose. Since the crystallinity and the molecular weight of both 
FDBC and BCP are the same, the difference in the degradation behaviour must be attributed to the difference in morphology between FDBC (loose nanofibrils) and BCP (interwoven dense structure). Different thermal degradation behaviour was also observed between carbonised FDBC and carbonised $\mathrm{BCP}$. This can be attributed to the differences between the starting structures of FDBC and BCP. The pyrolysis process involves the removal of non-carbonaceous (hydrogen and oxygen) material, leaving behind the skeletal structure of polyaromatic carbon [14,52]. Due to the loose fibrous form of $\mathrm{FDBC}$, the carbonisation of FDBC might have resulted in the possible formation of more defective carbon compared to the carbonisation of $\mathrm{BCP}$, which produced more graphitic carbon. In addition to this, the fabrication of $\mathrm{BCP}$ stretched the cellulose nanofibrils and this stretching of nanofibrils will result in improved orientation of graphite crystallites [53].

\subsection{Raman spectra of $\mathrm{BC}$ derived carbon}

Fig 4 shows the Raman spectra of $\mathrm{BC}$ derived carbons, in the range of $1000 \mathrm{~cm}^{-1}$ and $2000 \mathrm{~cm}^{-1}$ wavenumbers. Two typical peaks for carbon centred around $1350 \mathrm{~cm}^{-1}$ and $1590 \mathrm{~cm}^{-1}$ can be observed and these peaks can be attributed to the disorganised carbon (D-band) and graphitic carbon (G-band), respectively with an $\mathrm{sp}^{2}$ configuration [54]. The fitted Raman spectra are shown as the dotted lines in Fig 4. Table 2 shows the D-band to G-band ratio (calculated using the integrated area of the fitted curves) and the in-plane graphitic crystallite size of the carbon crystallites. It can be seen that the carbon produced from BC possesses D- to G-band ratios comparable to commercially available CNF and the carbonised FDBC possessed more defective carbon $\left(\mathrm{I}_{\mathrm{D}} / \mathrm{I}_{\mathrm{G}}=2.74\right)$ compared to carbon derived from $\mathrm{BCP}\left(\mathrm{I}_{\mathrm{D}} / \mathrm{I}_{\mathrm{G}}=2.40\right)$. This may be due to its loose fibrous form, which possibly resulted in the formation of more defective carbon during the carbonisation process. Comparing carbonised $\mathrm{BCP}$ and carbonised and physically activated $\mathrm{BCP}$, the physical activation process resulted in more graphitic carbon. This is not surprising, as the activation process removes the defective carbon first [14]. The shift in iep to higher $\mathrm{pH}$ and the 
decreasing $\mathrm{I}_{\mathrm{D}} / \mathrm{I}_{\mathrm{G}}$ ratio indicates that the formation of graphitic carbon resulted in the loss of dissociable functional groups.

\subsection{Electric double layer capacitance of (activated) BC derived carbons and CNF}

The double layer capacitance of carbon samples derived from $\mathrm{BC}$ was examined using cyclic voltammetry $(\mathrm{CV})$ over a potential range of $-0.2 \mathrm{~V}$ to $0.2 \mathrm{~V}$ versus an $\mathrm{Ag} / \mathrm{AgCl}$ reference electrode. A typical CV profile at various scan rates is shown in Fig 5. The well-defined rectangular shape of the $\mathrm{CV}$ profile is an indication that the capacitive behaviour of the sample is predominantly due to electrostatic attraction [8] and that this capacitive behaviour is reversible [19]. It can be observed from Fig 5 that the CV profile is stable within the chosen potential window as no oxidation and reduction peaks are observed. The capacitance of carbon samples derived from $\mathrm{BC}$ and $\mathrm{CNF}$ at various scan rates is tabulated in Table 3. Carbonised $\mathrm{BCP}$ has the lowest capacitance, followed by carbonised FDBC and activated pyrolysed BCP. This result is consistent with the total surface area of the samples; carbonised BCP had the lowest surface area, followed by carbonised FDBC and activated pyrolysed BCP. Comparing the capacitance of these results with commercially available $\mathrm{CNF}$, the double layer capacitance of the nano-sized carbon derived from $\mathrm{BC}$ is 337 times (carbonised FDBC) and 520 times (activated pyrolysed $\mathrm{BCP}$ ) higher than that of commercially available CNF. This result is also consistent with the total surface area of the nano-sized carbon derived BC (see Table 1).

It can be seen from Table 3 that the capacitance values of carbon derived from BC are still lower than that of commercially available high performance activated carbon (YP-50F). This might be due to the high surface area of activated carbon, measured to be approximately $1938 \mathrm{~m}^{2}$

$\mathrm{g}^{-1}$ (Table 1). However, when comparing the surface area-normalised specific capacitance of all samples (specific capacitance divided by specific surface area of the sample), carbonised FDBC and activated pyrolysed BCP showed better performance compared to YP-50F. An area- 
normalised specific capacitance of $1617 \mathrm{~F} \mathrm{~cm}^{-2}$ and $659 \mathrm{~F} \mathrm{~cm}^{-2}$ were achieved for carbonised FDBC and activated pyrolysed BCP, respectively, compared to YP-50F of only $365 \mathrm{~F} \mathrm{~cm}^{-2}$. In addition to surface area, the double layer capacitance is also related to the thickness of the Helmholtz layer [9]. As a first approximation, the double layer capacitance is proportional to the surface area and inversely proportional to the thickness of the Helmholtz layer (equation 6):

$C=\frac{\varepsilon_{0} \varepsilon_{r} S}{d}$

where $C$ is the capacitance of the sample, $\varepsilon_{0}, \varepsilon_{r}, S$ and $d$ are the static permittivity of vacuum, static permittivity of the medium, surface area and thickness of the Helmholtz layer, respectively. It can also be seen that the capacitance of all the samples is dependent on the scanning rates

during the $\mathrm{CV}$ measurements. For example, at a scan rate of $10 \mathrm{mV} \mathrm{s}^{-1}$ the capacitance of activated and pyrolysed BCP decreased by as much as 30\% when compared to its capacitance at $1 \mathrm{mV} \mathrm{s}^{-1}$. Similar reduction was also observed for YP-50F. This is a direct result of the porous nature of all the carbon samples (see Table 1 for pore area of all the carbonaceous samples). When a higher scan rate is used, the carbonaceous samples behave like a small impedance element with the current will flow predominantly along the external surface and almost no current will flow down the pores [9].

\section{Conclusions}

A nano-carbon material was produced from bacterial cellulose $(\mathrm{BC})$ through pyrolysis and physical activation of $\mathrm{BC}$. It was found that the starting morphology of $\mathrm{BC}$, either as loose nanofibrils (freeze-dried) or dense paper, affects the properties of the $\mathrm{BC}$ derived carbon. When $\mathrm{BC}$ in its loose fibrous (freeze-dried) form was pyrolysed, a carbon nanofibre-like material was formed. However, it was not possible to physically activate this material due to its low carbon 
yield after pyrolysis. Dense BC paper, on the other hand, could be pyrolysed and physically activated by $\mathrm{CO}_{2}$. The total surface area of the $\mathrm{BC}$ derived carbon increased after physical activation as determined by BET surface area measurements. The D- to G-band ratio determined by Raman spectroscopy was found to be in the range of 2.2 to 2.8 , which is comparable to commercially available CNFs of 2.2. The electric double layer capacitance of the activated carbon derived from $\mathrm{BC}$ was found to be as high as $42 \mathrm{~F} \mathrm{~g}^{-1}$ (carbonised and activated $\mathrm{BCP}$ ) in $\mathrm{K}_{2} \mathrm{SO}_{4}$ electrolyte solution. This can be attributed to the high specific surface area of the materials. This high capacitance performance in electrolyte solution is much higher than the capacitance of commercially available CNF $\left(0.17 \mathrm{~F} \mathrm{~g}^{-1}\right)$ but still lower that that of commercially available activated carbon $\left(71 \mathrm{~F} \mathrm{~g}^{-1}\right)$. However, when comparing the area-normalised specific capacitance, carbonised FDBC and activated pyrolysed BCP stood out, showing a value of 1617 $\mathrm{F} \mathrm{cm}^{-2}$ and $659 \mathrm{~F} \mathrm{~cm}^{-2}$, respectively, compared to activated carbon of only $365 \mathrm{~F} \mathrm{~cm}^{-2}$. The good double layer capacitance performance shown by this nano-carbon material provides a potential new active material for supercapacitors and capacitive deionisation technology.

\section{Acknowledgements}

The authors would like to thank the UK Engineering and Physical Research Council (EPSRC) for funding KYL (EP/F028946/1) and the Challenging Engineering programme of the EPSRC for funding JJB (EP/E007538/1). The authors would like to thank Prof. Marc Anderson from the University of Wisconsin, Madison USA for helpful discussions.

\section{References}

1. Staiti P, Minutoli M, Lufrano F (2002) All solid electric double layer capacitors based on Nafion ionomer. Electrochim Acta 47 (17):2795-2800 
2. Shi H (1996) Activated carbons and double layer capacitance. Electrochim Acta 41 (10):16331639

3. Taniguchi A, Fujioka N, Ikoma M, Ohta A (2001) Development of nickel/metal-hydride batteries for EVs and HEVs. J Power Sources 100 (1-2):117-124

4. Scrosati B, Garche J (2010) Lithium batteries: Status, prospects and future. J Power Sources 195 (9):2419-2430

5. Jayalakshmi M, Balasubramanian K (2008) Simple Capacitors to Supercapacitors - An Overview. Int J Electrochem Sci 3 (11):1196-1217

6. Lee J, Yoon S, Hyeon T, Oh SM, Kim KB (1999) Synthesis of a new mesoporous carbon and its application to electrochemical double-layer capacitors. Chem Commun (21):2177-2178

7. Lee SI, Mitani S, Park CW, Yoon SH, Korai Y, Mochida I (2005) Electric double-layer capacitance of microporous carbon nano spheres prepared through precipitation of aromatic resin pitch. J Power Sources 139 (1-2):379-383

8. Xu B, Wu F, Su YF, Cao GP, Chen S, Zhou ZM, Yang YS (2008) Competitive effect of KOH activation on the electrochemical performances of carbon nanotubes for EDLC: Balance between porosity and conductivity. Electrochim Acta 53 (26):7730-7735

9. Kotz R, Carlen M (2000) Principles and applications of electrochemical capacitors. Electrochim Acta 45 (15-16):2483-2498

10. Kotz R, Gobrecht J, Stucki S, Pixley R (1986) Insitu Rutherford Backscattering Spectroscopy for Electrochemical Interphase Analysis. Electrochim Acta 31 (2):169-172

11. Ardizzone S, Fregonara G, Trasatti S (1990) Inner and Outer Active Surface of Ruo2 Electrodes. Electrochim Acta 35 (1):263-267

12. Naoi K, Suematsu S (1998) Advances in electrochemical capacitors - 3. Electrochemical capacitors using conducting polymers. Denki Kagaku 66 (9):896-903

13. Arbizzani C, Mastragostino M, Meneghello L (1996) Polymer-based redox supercapacitors: A comparative study. Electrochim Acta 41 (1):21-26

14. Rodriguez-Reinoso F, Molina-Sabio M (1992) Activated carbons from lignocellulosic materials by chemical and/or physical activation: An overview. Carbon 30 (7):1111-1118

15. Frackowiak E, Beguin F (2001) Carbon materials for the electrochemical storage of energy in capacitors. Carbon 39 (6):937-950

16. Honda Y, Ono T, Takeshige M, Morihara N, Shiozaki H, Kitamura T, Yoshikawa K, Morita M, Yamagata M, Ishikawa M (2009) Effect of MWCNT Bundle Structure on Electric DoubleLayer Capacitor Performance. Electrochem Solid State Lett 12 (3):A45-A49

17. Mukhopadhyay I, Suzuki Y, Kawashita T, Yoshida Y, Kawasaki S (2010) Studies on Surface Functionalized Single Wall Carbon Nanotube for Electrochemical Double Layer Capacitor Application. J Nanosci Nanotechnol 10 (6):4089-4094

18. Yamada Y, Kimizuka O, Tanaike O, Machida K, Suematsu S, Tamamitsu K, Saeki S, Hatori H (2009) Capacitor Properties and Pore Structure of Single- and Double-Walled Carbon Nanotubes. Electrochem Solid State Lett 12 (3):K14-K16

19. Kalpana D, Cho SH, Lee SB, Lee YS, Misra R, Renganathan NG (2009) Recycled waste paper-A new source of raw material for electric double-layer capacitors. J Power Sources 190 (2):587-591

20. Li X, Han C, Chen X, Shi C (2010) Preparation and performance of straw based activated cabron for supercapacitor in non-aqueous electrolytes. Micropor Mesopor Mat 131 (1-3):303-309 21. Liu W, Soneda Y, Kodama M, Yamashita J, Hatori H (2007) Low-temperature preparation and electrochemical capacitance of WC/carbon composites with high specific surface area. Carbon 45 (14):2759-2767 
22. Klijanienko A, Lorenc-Grabowska E, Gryglewicz G (2008) Development of mesoporosity during phosphoric acid activation of wood in steam atmosphere. Bioresour Technol 99 (15):7208-7214

23. El-Hendawy ANA, Alexander AJ, Andrews RJ, Forrest G (2008) Effects of activation schemes on porous, surface and thermal properties of activated carbons prepared from cotton stalks. Journal of Analytical and Applied Pyrolysis 82 (2):272-278

24. Girgis BS, Smith E, Louis MM, El-Hendawy ANA (2009) Pilot production of activated carbon from cotton stalks using H3PO4. J Anal Appl Pyrol 86 (1):180-184

25. Deng H, Yang L, Tao GH, Dai JL (2009) Preparation and characterization of activated carbon from cotton stalk by microwave assisted chemical activation-Application in methylene blue adsorption from aqueous solution. J Hazard Mater 166 (2-3):1514-1521

26. Phan NH, Rio S, Faur C, Le Coq L, Le Cloirec P, Nguyen TH (2006) Production of fibrous activated carbons from natural cellulose (jute, coconut) fibers for water treatment applications. Carbon 44 (12):2569-2577

27. Tan IAW, Hameed BH, Ahmad AL (2007) Equilibrium and kinetic studies on basic dye adsorption by oil palm fibre activated carbon. Chem Eng J 127 (1-3):111-119

28. Tan IAW, Ahmad AL, Hameed BH (2008) Preparation of activated carbon from coconut husk: Optimization study on removal of 2,4,6-trichlorophenol using response surface methodology. J Hazard Mater 153 (1-2):709-717

29. Ncibi MC, Jeanne-Rose V, Mahjoub B, Jean-Marius C, Lambert J, Ehrhardt JJ, Bercion Y, Seffen M, Gaspard S (2009) Preparation and characterisation of raw chars and physically activated carbons derived from marine Posidonia oceanica (L.) fibres. J Hazard Mater 165 (13):240-249

30. Ishida O, Kim DY, Kuga S, Nishiyama Y, Brown RM (2004) Microfibrillar carbon from native cellulose. Cellulose 11 (3-4):475-480

31. Kim DY, Nishiyama Y, Wada M, Kuga S (2001) Graphitization of highly crystalline cellulose. Carbon 39 (7):1051-1056

32. Kuga S, Kim DY, Nishiyama Y, Brown RM (2002) Nanofibrillar carbon from native cellulose. Mol Cryst Liquid Cryst 387:237-243

33. Shopsowitz KE, Hamad WY, MacLachlan MJ (2011) Chiral Nematic Mesoporous Carbon Derived From Nanocrystalline Cellulose. Angewandte Chemie-International Edition 50 (46):10991-10995. doi:10.1002/anie.201105479

34. Silva R, Al-Sharab J, Asefa T (2012) Edge-Plane-Rich Nitrogen-Doped Carbon Nanoneedles (CNNs) and Efficient Metal-Free-Electrocatalysts. Angewandte Chemie-International Edition. doi:10.1002/anie. 201201742

35. Lee KY, Blaker JJ, Bismarck A (2009) Surface functionalisation of bacterial cellulose as the route to produce green polylactide nanocomposites with improved properties. Compos Sci Technol 69 (15-16):2724-2733

36. Toyosaki H, Naritomi T, Seto A, Matsuoka M, Tsuchida T, Yoshinaga F (1995) Screening of Bacterial Cellulose-Producing Acetobacter Strains Suitable for Agitated Culture. Biosci Biotechnol Biochem 59 (8):1498-1502

37. Knight DS, White WB (1989) Characterization of Diamond Films by Raman-Spectroscopy. J Mater Res 4 (2):385-393

38. Baldan MR, Almeida EC, Azevedo AF, Goncalves ES, Rezende MC, Ferreira NG (2007) Raman validity for crystallite size L-a determination on reticulated vitreous carbon with different graphitization index. Appl Surf Sci 254 (2):600-603 
39. Tashima D, Taniguchi M, Fujikawa D, Kijima T, Otsubo M (2009) Performance of electric double layer capacitors using nanocarbons produced from nanoparticles of resorcinolformaldehyde polymers. Mater Chem Phys 115 (1):69-73

40. Show Y, Imaizumi K (2006) Decrease in equivalent series resistance of electric double-layer capacitor by addition of carbon nanotube into the activated carbon electrode. Diam Relat Mat 15 (11-12):2086-2089

41. Huidobro A, Pastor AC, Rodriguez-Reinoso F (2001) Preparation of activated carbon cloth from viscous rayon - Part IV. Chemical activation. Carbon 39 (3):389-398

42. Hunter RJ (1993) Introduction to modern colloid science. Oxford University Press Inc., New York

43. Bismarck A, Wuertz C, Springer J (1999) Basic surface oxides on carbon fibers. Carbon 37 (7):1019-1027

44. Fuente E, Menendez JA, Suarez D, Montes-Moran MA (2003) Basic surface oxides on carbon materials: A global view. Langmuir 19 (8):3505-3511

45. Ishimaru K, Hata T, Bronsveld P, Meier D, Imamura Y (2007) Spectroscopic analysis of carbonization behavior of wood, cellulose and lignin. J Mater Sci 42 (1):122-129

46. Oberlin A, Villey M, Combaz A (1980) Influence of Elemental Composition on Carbonization - Pyrolysis of Kerosene Shale and Kuckersite. Carbon 18 (5):347-353

47. Villey M, Oberlin A, Combaz A (1979) Influence of Elemental Composition on Carbonization Pyrolysis of Sporopollenin and Lignite as Models of Kerogens. Carbon 17 (1):7786

48. Julien F, Baudu M, Mazet M (1998) Relationship between chemical and physical surface properties of activated carbon. Water Res 32 (11):3414-3424

49. Seifert M, Hesse S, Kabrelian V, Klemm D (2004) Controlling the water content of never dried and reswollen bacterial cellulose by the addition of water-soluble polymers to the culture medium. J Polym Sci Pol Chem 42 (3):463-470

50. Cheng K-C, Catchmark JM, Demirci A (2009) Enhanced production of bacterial cellulose by using a biofilm reactor and its material property analysis. J Bio Eng 3 (12). doi:10.1186/17541611-3-12

51. Um IC, Ki CS, Kweon HY, Lee KG, Ihm DW, Park YH (2004) Wet spinning of silk polymer - II. Effect of drawing on the structural characteristics and properties of filament. Int J Biol Macromol 34 (1-2):107-119

52. Plaisantin H, Pailler R, Guette A, Daude G, Petraud M, Barbe B, Birot M, Pillot JP, Olry P (2001) Conversion of cellulosic fibres into carbon fibres: a study of the mechanical properties and correlation with chemical structure. Compos Sci Technol 61 (14):2063-2068

53. Morgan P (2005) Carbon fibers and their composites. Crc Press-Taylor \& Francis Group, Boca Raton

54. Wang Y, Serrano S, Santiago-Aviles JJ (2003) Raman characterization of carbon nanofibers

prepared using electrospinning. Synth Met 138 (3):423-427 


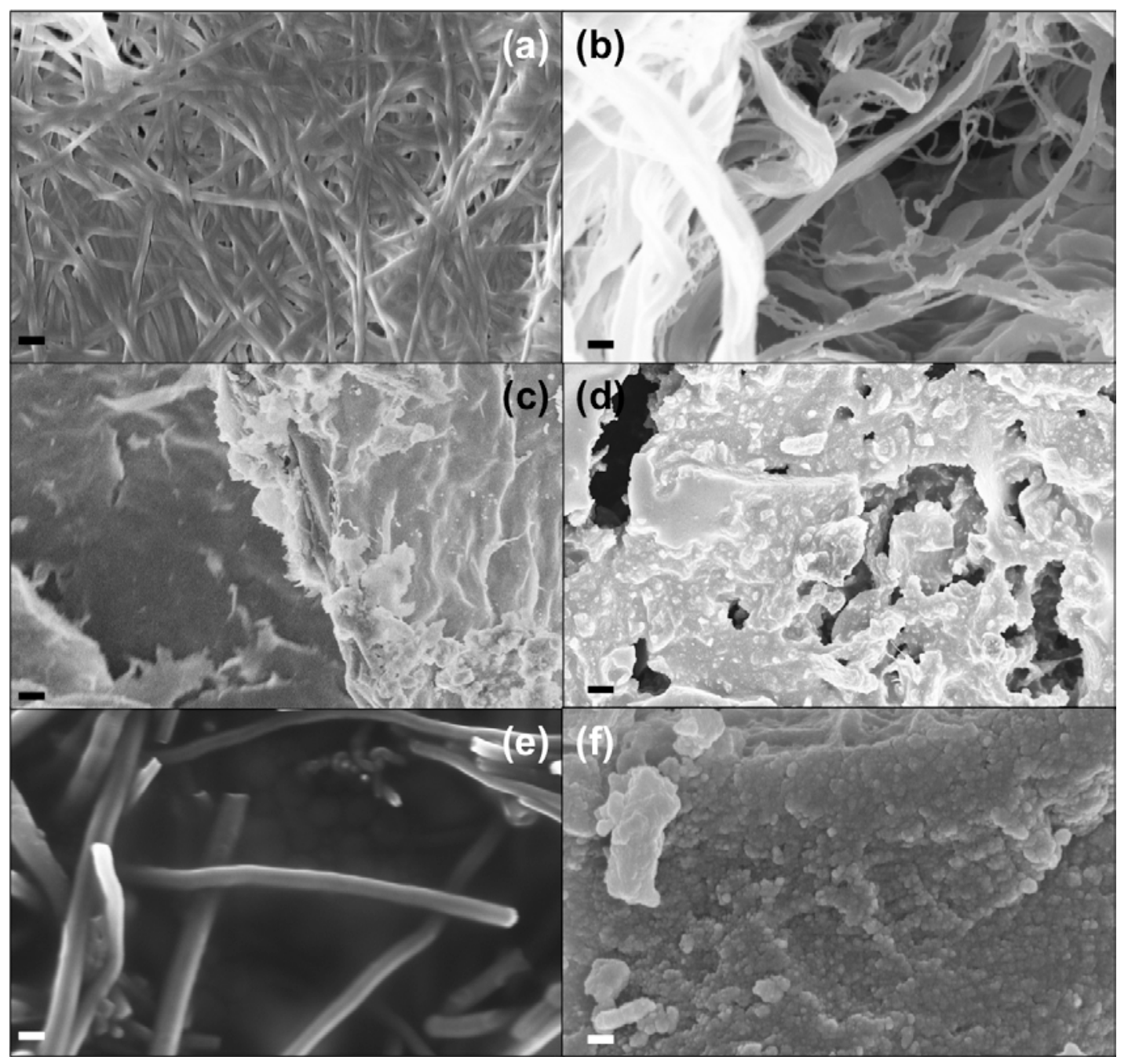

Fig 1. Scanning electron micrographs of (a) Freeze-dried BC, (b) carbonised freeze-dried BC, (c) carbonised BC paper, (d) activated pyrolysed BC paper, (e) carbon nanofibres and (f) activated carbon YP-50F. The scale bar in figures (a), (b), (e) and (f) represent $200 \mathrm{~nm}$ whereas the scale bar in figures (c) and (d) represent 1 micrometre. 


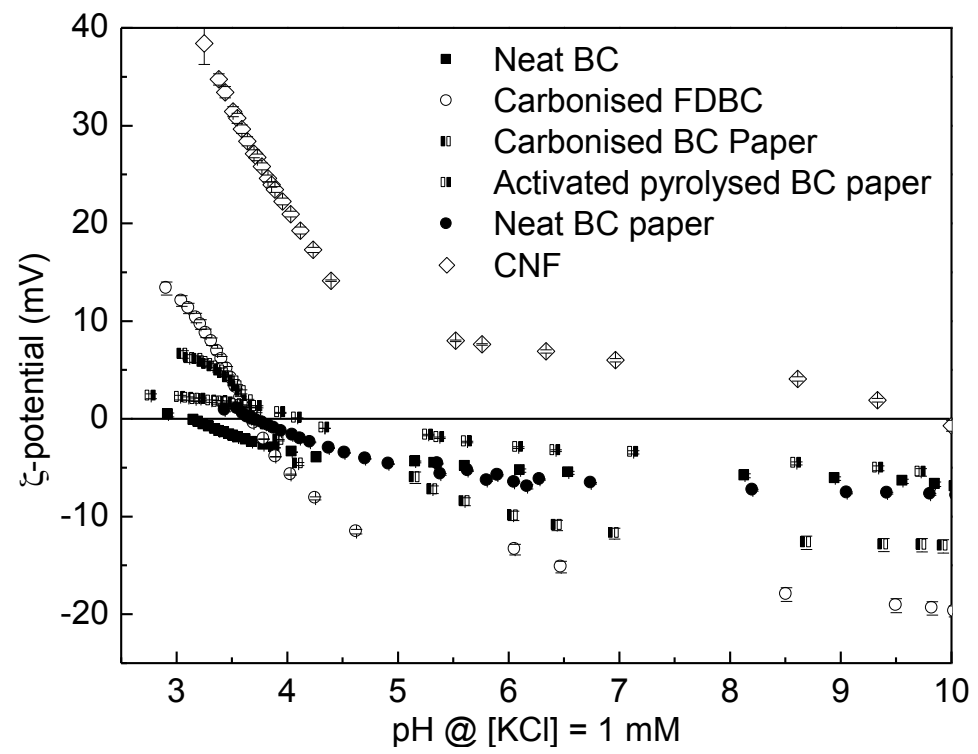

Fig 2. pH dependent $\zeta$-potential of neat $\mathrm{BC}$ and carbon samples derived from $\mathrm{BC}$.

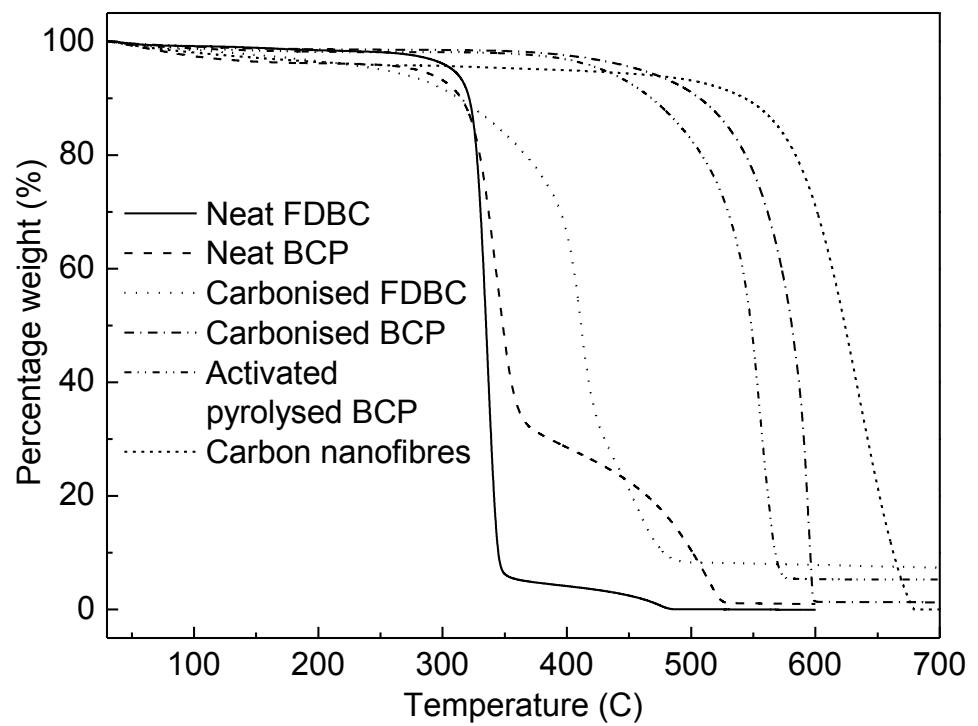

Fig 3. Thermal degradation behaviour of neat $B C$ and carbon samples derived from $B C$ in air. 
(b)

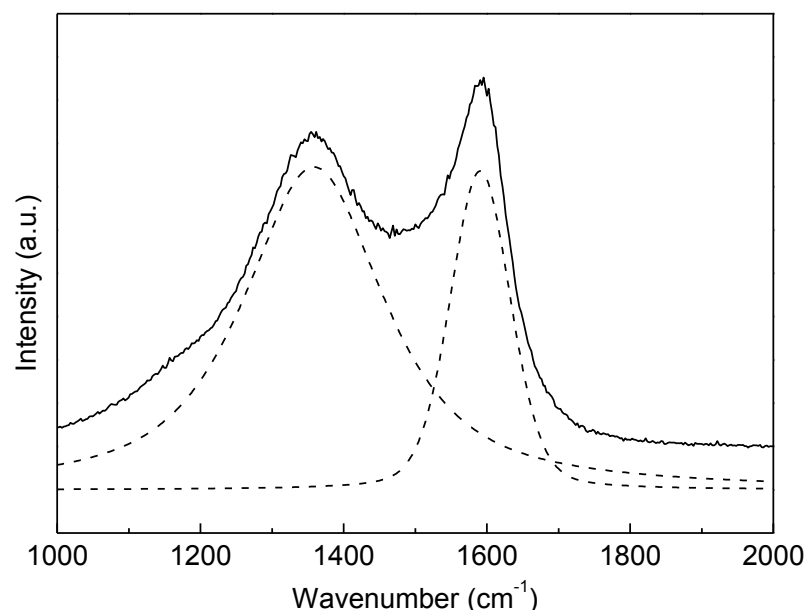

(c)
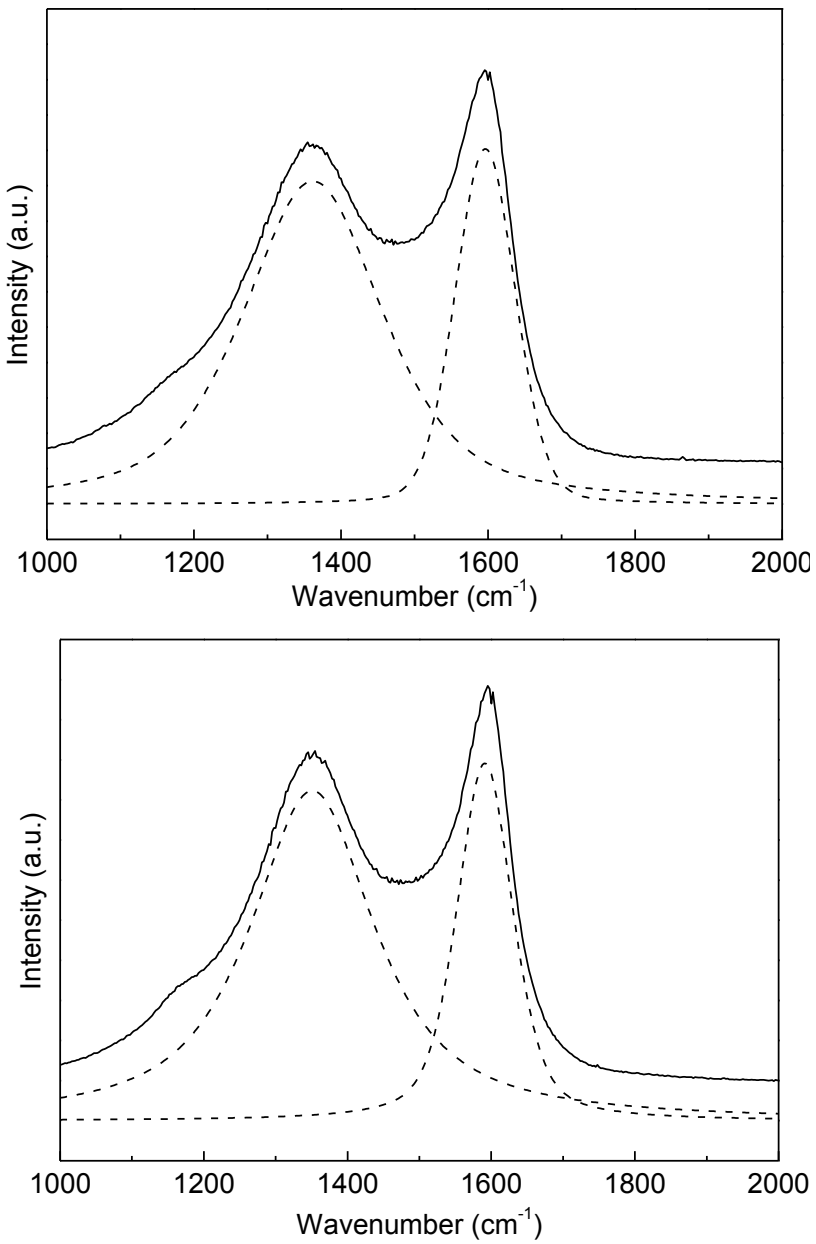

Fig 4. Raman spectra of carbon samples derived from BC. (a) Carbonised FDBC, (b) carbonised BC paper and (c) activated pyrolysed $\mathrm{BC}$ paper. 


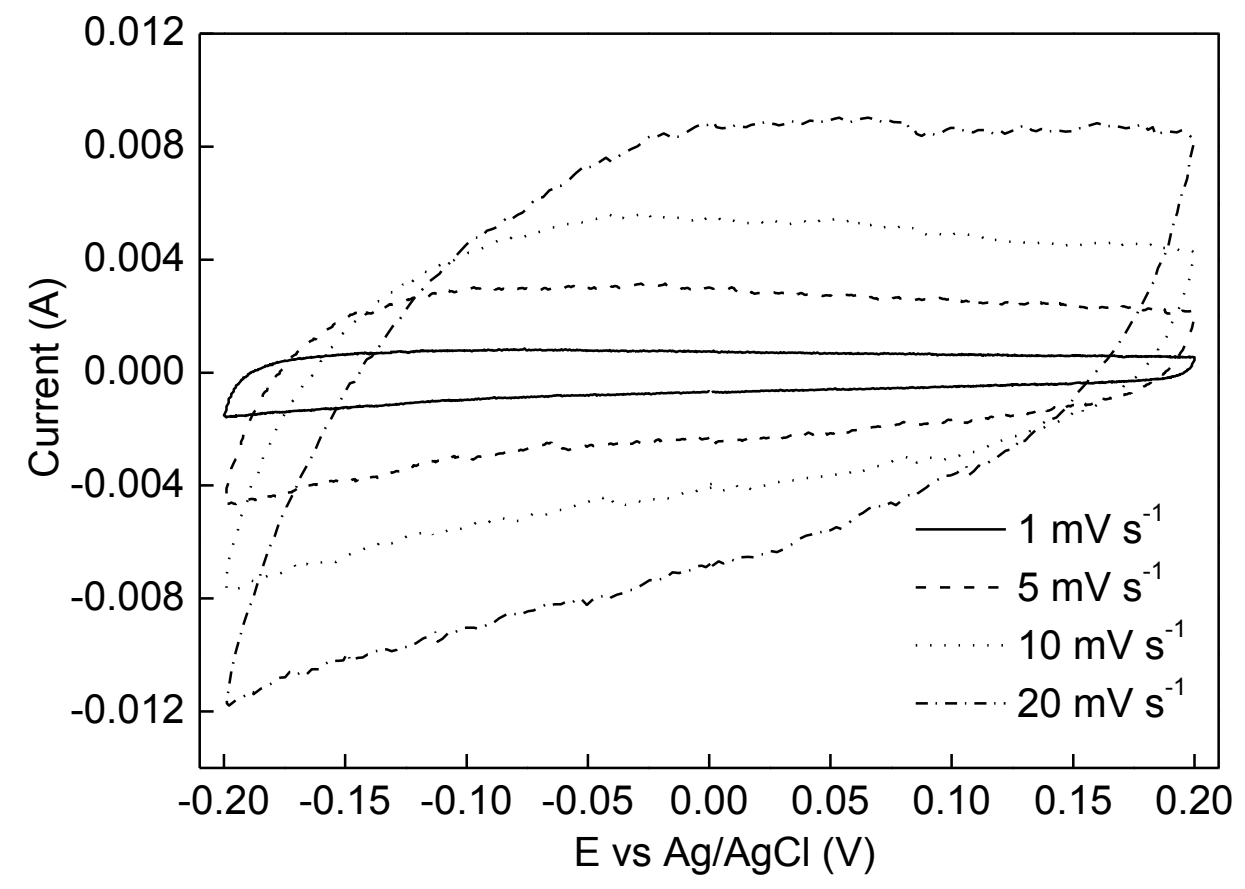

Fig 5. Cyclic voltammetry of activated pyrolysed BC paper at different scan rates. 
Table 1. Density $(\rho)$, burn-off $(\Delta \mathrm{m})$, carbon yield $(\Delta \mathrm{Y})$, total surface area $\left(\mathrm{S}_{\text {total }}\right)$, external surface area $\left(\mathrm{S}_{\text {ext }}\right)$, micropore surface area $\left(S_{\text {pore }}\right)$ and pore width $\left(d_{\text {pore }}\right)$, respectively of neat $B C$ and carbon samples derived from BC.

\begin{tabular}{|c|c|c|c|c|c|c|}
\hline Sample & $\begin{array}{l}\rho \\
\left(\mathrm{g} \mathrm{cm}^{-3}\right)\end{array}$ & $\begin{array}{l}\Delta m \text { or } \Delta Y \\
(\%)\end{array}$ & $\begin{array}{l}S_{\text {total }} \\
\left(\mathrm{m}^{2} \mathrm{~g}^{-1}\right)\end{array}$ & $\begin{array}{l}S_{\text {ext }} \\
\left(m^{2} g^{-1}\right)\end{array}$ & $\begin{array}{l}S_{\text {pore }} \\
\left(\mathrm{m}^{2} \mathrm{~g}^{-1}\right)\end{array}$ & $\begin{array}{l}d_{\text {pore }} \\
(\mathrm{nm})\end{array}$ \\
\hline FDBC & $1.42 \pm 0.04$ & - & $54.54 \pm 0.03$ & 54.38 & 0.16 & 15.2 \\
\hline $\mathrm{BCP}$ & $1.54 \pm 0.01$ & - & $7.29 \pm 0.02$ & 6.42 & 0.87 & 8.86 \\
\hline $\begin{array}{l}\text { Carbonised } \\
\text { FDBC }\end{array}$ & $1.19 \pm 0.10$ & 2.3 & $166.78 \pm 0.17$ & 145.10 & 21.68 & 7.95 \\
\hline $\begin{array}{l}\text { Carbonised } \\
\text { BCP }\end{array}$ & $1.65 \pm 0.02$ & 20.3 & $14.56 \pm 0.25$ & 0.83 & 13.73 & 1.95 \\
\hline $\begin{array}{l}\text { Activated } \\
\text { pyrolysed BCP }\end{array}$ & $2.07 \pm 0.01$ & 2.9 & $630.96 \pm 11.18$ & 95.34 & 535.62 & 2.23 \\
\hline $\mathrm{CNF}$ & $1.67 \pm 0.12$ & - & $37.18 \pm 0.16$ & 30.26 & 6.92 & 7.60 \\
\hline YP-50F & $2.38 \pm 0.06$ & - & $1938.50 \pm 34.55$ & 435.11 & 1503.39 & 2.05 \\
\hline
\end{tabular}

- Indicates carbon yield, $\Delta \boldsymbol{Y}$

+ Indicates burn-off, $\Delta m$

Table 2. Summary of the iso-electric point (iep), the plateau of $\xi_{\text {-potential }}\left(\xi_{\text {plateau }}\right.$ ), the onset thermal degradation temperature $\left(T_{d}\right)$, D-band to $G$-band ratio $\left(I_{D} / I_{G}\right)$ and the in-plane graphitic crystallite size $\left(L_{a}\right)$ of neat $\mathrm{BC}$ and carbon samples derived from $\mathrm{BC}$.

\begin{tabular}{lcclll}
\hline Sample & iep & $\zeta_{\text {plateau }}(\mathbf{m V})$ & $\mathbf{T}_{\mathbf{d}}\left({ }^{\circ} \mathbf{C}\right)$ & $\mathbf{I}_{\mathbf{D}} / \mathbf{I}_{\mathbf{G}}$ & $\mathbf{L}_{\mathbf{a}}(\AA)$ \\
\hline FDBC & 3.1 & $-6.0 \pm 0.2$ & 277 & - & - \\
BCP & 3.7 & $-6.9 \pm 0.2$ & 268 & - & - \\
Carbonised FDBC & 3.7 & $-18.3 \pm 0.8$ & 279 & $2.74 \pm 0.01$ & $16.06 \pm 0.04$ \\
Carbonised BCP & 3.8 & $-12.7 \pm 0.2$ & 432 & $2.40 \pm 0.01$ & $18.34 \pm 0.03$ \\
Activated pyrolysed BCP & 4.1 & $-4.4 \pm 0.4$ & 410 & $2.27 \pm 0.01$ & $19.42 \pm 0.04$ \\
CNF & 9.8 & $+6.5 \pm 0.7$ & 497 & $2.27 \pm 0.04$ & $19.35 \pm 0.38$ \\
YP-50F & & & 540 & $2.08 \pm 0.03$ & $4.19 \pm 0.22$ \\
\hline
\end{tabular}


Table 3. Capacitance of various carbon samples derived from BC at different scan rates. CNF and YP-50F were used as a comparison.

\begin{tabular}{lllll}
\hline \multirow{2}{*}{ Sample } & \multicolumn{4}{c}{ Capacitance (F/g) } \\
\cline { 2 - 5 } & $\mathbf{1} \mathbf{~ m V ~ s}$ & $\mathbf{5 ~} \mathbf{~ V ~ s}^{-1}$ & $\mathbf{1 0 ~} \mathbf{~ V ~ s}$ & $\mathbf{2 0 ~} \mathbf{~ V ~ s ~ s}^{-1}$ \\
\hline Carbonised FDBC & $26.97 \pm 2.22$ & $14.72 \pm 0.18$ & $11.32 \pm 0.02$ & $6.40 \pm 0.21$ \\
Carbonised BCP & $0.06 \pm 0.01$ & $0.03 \pm 0.01$ & $0.02 \pm 0.01$ & $0.02 \pm 0.01$ \\
Activated pyrolysed BCP & $41.59 \pm 1.15$ & $31.82 \pm 0.49$ & $28.08 \pm 0.36$ & $23.01 \pm 0.29$ \\
CNF & $0.08 \pm 0.01$ & $0.04 \pm 0.01$ & $0.04 \pm 0.01$ & $0.04 \pm 0.01$ \\
YP-50F & $70.85 \pm 1.86$ & $52.92 \pm 0.62$ & $49.73 \pm 0.78$ & $44.98 \pm 1.06$ \\
\hline
\end{tabular}

Table 4. Area-normalised specific capacitance of various carbon samples derived from BC at different scan rates. CNF and YP-50F were used as a comparison.

\begin{tabular}{|c|c|c|c|c|}
\hline \multirow{2}{*}{ Sample } & \multicolumn{4}{|c|}{ Area-normalised specific capacitance $\left(\mathrm{F} / \mathrm{cm}^{2}\right)$} \\
\hline & $1 \mathrm{mVs}^{-1}$ & $5 \mathrm{mV} \mathrm{s}^{-1}$ & $10 \mathrm{mV} \mathrm{s}^{-1}$ & $20 \mathrm{mV} \mathrm{s}^{-1}$ \\
\hline Carbonised FDBC & $1617 \pm 133$ & $883 \pm 11$ & $679 \pm 1$ & $384 \pm 13$ \\
\hline Carbonised BCP & $41 \pm 7$ & $21 \pm 7$ & $14 \pm 7$ & $14 \pm 7$ \\
\hline Activated pyrolysed BCP & $659 \pm 18$ & $504 \pm 8$ & $445 \pm 6$ & $365 \pm 5$ \\
\hline $\mathrm{CNF}$ & $22 \pm 3$ & $11 \pm 3$ & $11 \pm 3$ & $11 \pm 3$ \\
\hline YP-50F & $365 \pm 10$ & $273 \pm 3$ & $257 \pm 4$ & $232 \pm 5$ \\
\hline
\end{tabular}

